\title{
Trends in ethical and legal frameworks for the use of human biobanks
}

\author{
A. Cambon-Thomsen*, E. Rial-Sebbag* and B.M. Knoppers ${ }^{\#}$
}

ABSTRACT: Numerous studies of genetic epidemiology and post-genomics in respiratory diseases rely on the use of biobanks, defined as organised biological sample collections with associated personal and clinical data. The use of biobanks is increasing and raises several ethical issues. What are the ethical trends and legal frameworks in the post-genomic era? Are there new issues in relation to the developments of techniques and new study designs? How does this affect the clinician's attitudes and relationship with the patients?

The main ethical issues encountered are: informed consent; confidentiality; secondary use of samples and data over time; return of results; and data sharing. Different levels and modalities of dealing with such issues are identified and vary from legally binding measures to "soft" regulations, such as ethical recommendations by various committees or professional organisations.

A further level of complexity appears with the increasing international dimension of such activities in a context in which national positions vary on those topics. There is a tension between a necessary level of diversity in ethical positions and an indispensable common pedestal of principles and procedures to manage these issues in order to foster research.

Current legal and ethical trends favour the facilitation of secondary use of samples, more biobank openness, balanced with a growing attention to dialogue and public/stakeholder consultation, an increased role for research ethics committees and more sophisticated data protection and governance structures.

KEYWORDS: Bioethics, confidentiality, genetic databases, human biobanks, informed consent, secondary use

A $\mathrm{s}$ the impact of molecular and genomic data grows in epidemiology [1, 2], numerous studies of genetic epidemiology and post-genomics research in respiratory diseases rely increasingly on the use of human biobanks [3]. Biobanking, the organised collection of biological samples and associated data, ranges in scope from small collections of samples in academic or hospital settings to large-scale national repositories. The organisation and the use of such resources raises ethical issues [4, 5]. Although biobanking is not new, its considerable development during the past $10-15$ yrs, in the context of genomic and post-genomic research, has been accompanied by the generation of numerous documents addressing their ethical challenges.

\section{WHAT IS AT STAKE?}

"The rapid pace of change has produced two powerful, but conflicting, social reactions. On the one hand, there is very strong public support for breakthroughs promising better medical diagnosis and treatments and, on the other, there are

Previous articles in this series: No. 1: Le Souëf PN, Candelaria P, Goldblatt J. Evolution and respiratory genetics. Eur Respir J 2006; 28: 1258-1263. No. 2: Martinez FD. Genes, environments, development and asthma: a reappraisal. Eur Respir J 2007; 29: 179-184. No. 3: Shapiro SD. Transgenic and gene-targeted mice as models for chronic obstructive pulmonary disease. Eur Respir J 2007; 29: 375-378. No. 4: Holgate ST, Davies DE, Powell RM, Howarth PH, Haitchi HM, Holloway JW. Local genetic and environmental factors in asthma disease pathogenesis: chronicity and persistence mechanisms. Eur Respir J 2007; 29: 793-803. No. 5: Hall IP, Sayers I. Pharmacogenetics and asthma: false hope or new dawn? Eur Respir J 2007; 29: 1239-1245.

AFFILIATIONS

*Inserm, U 558, Dept of Epidemiology, Health Economics and Public Health University Paul Sabatier, Toulouse, France.

${ }^{\text {\#} C e n t r e ~ d e ~ R e c h e r c h e ~ e n ~ D r o i t ~ P u b l i c, ~}$ University of Montreal, Montreal, QC Canada.

\section{CORRESPONDENCE}

A. Cambon-Thomsen, Inserm U 558 , Dept of Epidemiology, Health Economics and Public Health, Faculty of medicine, 37 allées Jules Guesde 31073 Toulouse, Cedex, France. Fax: 33 561145623. E-mail: cambon@cict.fr

Received:

December 192006 Accepted after revision: February 282007

SUPPORT STATEMENT

The study was supported in part by the FP6 EU Network of excellence GAALEN (Contract Food-CT-2004-506378), the FP6 EU Coordination Action PHOEBE (Contract No. LSHG-CT-2006-518148), the FP6 Integrated Project Riset

(Contract No. FP6-IP512090), Génopole Toulouse Midi-Pyrénées, DRESS (Research Mission attached to the Minister for Employment, Labour and Social Cohesion and to the Ministry for Health and Social Welfare System) in connection with the 2004 programme "Biomedical sciences, health and society" of the Centre National de la Recherche Scientifique, and an Action Concertée Incitative Internationalisation des SHS (No. 042 533), Ministry for National Education, Higher Education and Research: GenPos. B.M. Knoppers was sponsored by Genome Quebec and Genome Canada and participated in this work with the additional support of a Excellance-Chair Pierre de Fermat in Toulouse from Midi-Pyrénées Regional Council.

STATEMENT OF INTEREST

None declared.

European Respiratory Journal Print ISSN 0903-1936 Online ISSN 1399-3003 
anxieties about increased loss of privacy and the potential for genetic discrimination, as well as about the capacity to regulate genetic science in the public interest" [6]. Although the guiding principles to respond to those concerns are generally the same, human rights and fundamental freedoms (e.g. autonomy, privacy, nondiscrimination and nonstigmatisation), their implementation may be extremely variable.

Different logics of regulation for the use and procurement of biological samples and data have appeared both at the national and international levels, sometimes through specific legally binding instruments or by general regulatory texts [7-9]. Over the years, new questions, difficulties and solutions appear. The result is that there is considerable confusion and the consideration of this maze of literature and procedures may be difficult to get through. This is enhanced by the fact that the definitions of biobanks are variable and the set of terms used leads to ambiguities throughout the regulatory frameworks $[10,11]$. Nevertheless, although the field is still evolving, general trends can be underlined for issues that encompass initial information and consent, secondary uses, confidentiality, samples and data exchange and benefit sharing.

Moreover, the contexts can be very different according to the type of studies performed [12, 13] and the different study designs may call for different ethical issues. The use of different types of biological samples, from DNA genotyping to proteomics, may provide results with varying individual and population consequences. Ethical issues themselves directly impact on the methodology used and this has consequences on the information clinicians have to deliver to the patients. In addition, it is worth mentioning that at the international legal level, the two main axes, biomedical research and therapeutic applications, tend to be regulated by different guidelines, while their frontiers are somewhat flexible. Through interdisciplinary exchanges and training, regulators acquire a deeper understanding of the reality of the evolving research using biobanks. Researchers and clinicians develop an increased awareness of the issues, the regulatory framework and the administrative modalities for the ethical conduct of biobanking that become even more complex at the international level. The present study aims to contribute to such a process.

The questions to be addressed are as follows. What are the main ethical issues encountered in the construction and the use of biobanks, especially in the context of asthma and allergy research, as an example of chronic complex diseases involving environmental and genetic factors, often affecting children and requiring long-term follow-up? What are the recent ethical and legal frameworks that provide guidance in the post-genomic era? What are the practical consequences for clinicians who ask patients to get involved in such a project? Can a guiding logic of practical use be found in this complex field?

\section{WHERE TO FIND INFORMATION}

The main issues can be identified by concentrating on literature at a national or international level from 2000-2006 [7, 14-16]. The most controversial but well-documented ethical aspects are discussed later and an analysis of some recent regulatory texts addressing these points outlines a cautious combination of the current relevant trends. The principal documents of reference for the supra-national level are given in table 1, which lists the major relevant international instruments published or modified between the years 2000-2006. The documents can be confronted with the choice made at the national level for managing ethical aspects [14, 15, 17-34], whereby two main attitudes appear. Either national legislation specific to biological material and/or data collections appear, as is the case in Iceland, Norway, Sweden, Estonia and Latvia,

\section{TABLE 1 International normative instruments regarding biomedical research and biobanks 2000-2006}

\section{Organisation}

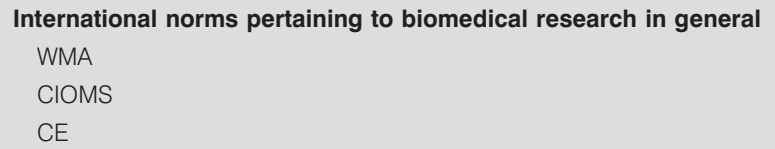

Ref.

$[17]$
$[18]$
$[19]$

$[20]$
$[21]$
$[22]$
$[23]$
$[24]$
$[25]$
$\left.6^{\bullet}-28^{+}\right]$

WMA: World Medical Association; CIOMS: Council for International Organizations of Medical Sciences; CE: Council of Europe; ESHG: European Society of Human Genetics; HUGO: Human Genome Organisation; WHO: World Health Organization; UNESCO: United Nations Educational, Scientific and Cultural Organization. \#: European Partnership on Patients' Rights and Citizens' Empowerment. '? these recommendations were prepared by a multidisciplinary expert group consulted by the European Commission. Although this document focuses on genetic testing, several recommendations address human biological material collections and associated data specifically. The report and the Conference proceedings are presented elsewhere [29]. ${ }^{+}$: although the scope of these directives is limited to therapeutic applications, the principles it lays down have implications for research. Data presented in an updated format from [15] with permission. 
TABLE 2 Similarities and differences in dealing with biobank ethical issues

Convergence: consensus

Divergence: controversial issues

\begin{tabular}{|c|c|}
\hline Consent & Adjusting traditional consent mechanisms to the specificity of biobanks \\
\hline Privacy/confidentiality & $\begin{array}{l}\text { Correlation between the degree of data identifiability (anonymous, } \\
\text { anonymised, double-coded, coded, identifiable) and the need to } \\
\text { re-contact participants, the possibility to withdraw from research, } \\
\text { the question of the return of results to participants and access to } \\
\text { data and samples by third parties }\end{array}$ \\
\hline $\begin{array}{l}\text { Dissemination of } \\
\text { results/information to } \\
\text { participants }\end{array}$ & $\begin{array}{l}\text { Requirement for comprehensive information prior to any large-scale } \\
\text { population biobank }\end{array}$ \\
\hline Discrimination risks & $\begin{array}{l}\text { The need to take into account potential risks of discrimination not only } \\
\text { at the time of recruitment but also when interpreting results }\end{array}$ \\
\hline $\begin{array}{l}\text { Governance and } \\
\text { monitoring }\end{array}$ & $\begin{array}{l}\text { The need for adequate scientific and ethical oversight at the time of } \\
\text { the biobank creation } \\
\text { Ongoing monitoring during the length of the project } \\
\text { Independence of the oversight institution and efficiency of its control } \\
\text { powers including sanctions }\end{array}$ \\
\hline Public involvement & $\begin{array}{l}\text { Promoting and reinforcing the dialogue between professionals and the } \\
\text { public: the public as an active participant } \\
\text { In the drafting of the ethical and legal framework governing population } \\
\text { biobanks } \\
\text { In the establishment of each population biobanks project } \\
\text { Involvement of patients associations when diseases are targeted }\end{array}$ \\
\hline $\begin{array}{l}\text { Resource sharing and } \\
\text { access }\end{array}$ & $\begin{array}{l}\text { Promoting the availability of scientific results to the widest audience } \\
\text { Facilitating the access to samples and data for research purposes }\end{array}$ \\
\hline Commercial aspects & $\begin{array}{l}\text { The need to elaborate benefit-sharing policies and to take into account } \\
\text { the potential commercial uses of the data held in population projects } \\
\text { resources }\end{array}$ \\
\hline
\end{tabular}

The width of the original consent to research and the secondary use of samples and data

Determining the adequate degree of identifiability Access to data

The right to know and not to know in the context of population biobanks: clinical interest, genetic counselling and interpretation of results; general versus individual results

Information provided to participants on the risk of discrimination and impacts on participation rate

Ethical oversight for international projects involving several countries: the nature of the control and bureaucratisation of the process

Governance: check and balances

Information, engagement, consent of the community or the population

Modalities of involvement

Length of time with restricted access to certain teams

Conditions of access of national resources to international users

Financing such enterprises: public projects versus private or semi-private projects

The status of genetic material: ownership, participants, financial gains (beneficiaries)

Involvement of private companies including industry

Data presented in an updated format from [15] with permission.

or amendments to existing ethical and/or legal standards are worked out, as in Quebec, Denmark, France, Germany and the UK. The terms of the debates are summarised below.

\section{THE ETHICAL ISSUES AT STAKE}

Among the ethical issues relevant to biobank activities, some are particularly controversial. These are shown in table 2 along with relevant discussion points. This section provides an overall picture of the issues.

\section{The "definitional" issue}

The definition of biobanks

This may not be seen as an ethical issue as such, but obviously what is included in the definition of a biobank has ethical consequences. Currently, there is enormous variation in the definitions used in regulatory literature. Some literature refers explicitly to biobanks, such as the Norwegian law in which the definition includes samples without explicit reference to data, i.e. a biobank is a collection of biological samples which are permanently preserved. Others include a gene bank (Estonia), a database of gene donors (Latvia) or several kinds of biobanks (diagnostic/research). However, in Sweden, a biobank begins with the preservation of one sample but refers only to samples that are identifiable (nonanonymous), omitting samples that do not allow tracing back to an identifiable individual.

In many cases, especially in the absence of specific legislation for biobanks, samples are considered as part of the human body on the one hand, yet, on the other hand, personal data related to the samples are regulated by separate legislation usually referring to databases and data protection legislation. In France, the term used in legal texts is "collection" while the National Advisory Bioethics Committee also use "collections", "biolibraries" or "biothèques" and "biobanks" [35].

With respect to biological samples and data, two trends are evident. The first makes a distinction between the physical biological samples themselves, which together constitute a collection, and the database made up of the information derived from these samples and their characterisation. The second trend, which currently predominates in the world of genomics, uses the term "database" to denote the physical samples as well as the information derived therefrom. This is 
the position adopted by United Nations Educational, Scientific and Cultural Organization (table 1). This is also clearly the trend in an ongoing initiative at World Health Organization (WHO) level [36]. With regard to both samples and data, WHO states "no regulatory framework for genetic databases has been developed to date that is global in scope yet developed with regional input, while being specific enough to provide practical guidance" [36]. In the most recent recommendation of the Council of Europe in March 2006 [20], biological materials are defined and are distinguished from "collections of biological materials". A definition of biobanks is also given but restricted to "population biobank" with the following features: "1) the collection has a population basis; 2) it is established, or has been converted to supply biological materials or data derived therefrom for multiple future research projects; 3) it contains biological materials and associated personal data, which may include or be linked to genealogical, medical and lifestyle data and which may be regularly updated; and 4) it receives and supplies materials in a organised manner" [20].

Finally, certain definitions may vary over time. For example, a virtual biobank has been defined as corresponding to entities which are soliciting donors via the web and sending the results to individuals or through physicians [3], whereas it may also be a biobank in which the biological samples remain in the remote site of original sampling and what is shared and centralised is information on those samples and the relevant contacts. In short, a clear definition of the type of biobank used in the context of genetic epidemiology or post-genomics projects is a key element for implementing proper ethical management. It is certainly useful for clinicians to be aware of such debates. A clear and explicit definition of the biobank considered for a given project is a prerequisite before starting to inform patients.

\section{Definitions related to identifiability}

Confidentiality has been described as a tower of Babel [11] or a maze [8]. There are different levels of identifiability; among the many names, the following were used in the 2006 Council of Europe recommendation. "1) Identifiable biological materials are those which, alone or in combination with associated data, allow the identification of the person concerned either directly or via the use of a code. In the latter case, the user of the biological materials may either have access to the code (coded materials) or not, which is under the control of a third party (linked anonymised materials). 2) Nonidentifiable biological materials are unlinked anonymised materials i.e. those which, alone or in combination with associated data, do not allow, with reasonable effort, the identification of the person concerned" [20]. These categories are referred to under different names in the various literatures, but those mentioned previously are the only European-level operational and official definitions that can be referred to, so far. They are key ethical elements in relation to the practical framework, which include: informed consent; withdrawal; secondary uses; public engagement and trust; and the return of results and information. Whereas the definition of biobanks is of use in understanding the global framework of patients' involvement, the understanding of the notion of identifiability is essential for each person to be able to assess the indivi dual consequences of participation; thus, clinicians have an essential role in clarifying the issue when communicating with patients.

\section{Informed consent}

Following the Nuremberg Code and through the Declaration of Helsinki, the inhumane exploitation of individuals in research was proscribed. Respect, by protecting autonomy through the process of obtaining consent, is important as it shows respect for the individual. The principle of informed consent is largely recognised and considered a pillar in the practice of bioethics. Although it does not in itself protect a person, informed consent allows individuals to exercise their fundamental right to decide whether and how their body, body parts and associated data will be used in research.

The application of informed consent encounters difficulties in the case of large-scale biobanks, which are often longitudinal and require extensive exchange of tissue and data. A sample is taken at a precise moment; it is then used over a number of years with knowledge and research questions evolving over time. This has generated numerous discussions, especially on broad consent and secondary use [37, 38]. The issue of secondary uses for stored human samples occurs as a rule and should not be disregarded, even though they are often unforeseeable at the time of sampling. The main ethical issues relate to: 1) the level of completeness of the information given; 2) the necessity of a new individual consent for each use; and 3) who will decide on this issue. Several views have been expressed, ranging from denying any use other than that initially stated to more flexible attitudes. Specific measures have been developed in the case of minors [39, 40] or those unable to consent. Several features of biobanks have generated debate about consent applicability, its limits, modalities and the conditions for waiving consent. This makes it the most controversial issue in the domain of biobanking [9, 37, 38, 4145]. A number of studies have been carried out to examine the opinions and attitudes of research participants on the matter of consent and issues in the context of biobanking [46-50], which showed a variety of patterns, with more concern focusing on confidentiality issues rather than the consent itself. Recently, the possibility of a somewhat broader consent for long-term projects, with extensive information upon recruitment, the right to withdraw, and advance consent given for re-contacting the participant for other studies, is emerging [48]. Several countries place more responsibility on research ethics committees in the decision of the necessity of new consent for a protocol explaining further use. However, a large heterogeneity exists between countries [17, 44, 51, 52].

\section{Withdrawal}

This is by far the most relevant area of concern in the domain of genetic studies and long-term biobanking. Safeguarding confidentiality is a paramount aspect of the protection of individuals and groups participating in biobanks. It is recognised that the degree of data protection (anonymous, anonymised, (double) coded, identifiable) is closely linked to questions of withdrawal from a research project, dissemination of results to participants (generally or individually), follow-up of participants and third-party access to research data. Unconcerted management of these elements can lead to contradictions or practical impossibilities. The right to withdraw is naturally mentioned in all consent forms for clinical assays, but how can this be implemented in practice for samples that are exchanged, data that are distributed in 
complex databases and, sometimes, for samples that undergo transformation into cell lines that can themselves be exchanged and duplicated? This needs to be carefully addressed with practical and feasible procedures set up and explained, otherwise it may be a concept with no reality and significance. There are a variety of situations ranging from identifying personal data (for which there is significant protection, very limited access and the possibility of withdrawal) to anonymised data (for which there is free access for research purposes, no possibility of re-contacting participants and no possibility of return of results or withdrawal from the project). When considering the confidentiality of data, problems of taxonomy arise. As mentioned previously, the vocabulary used to describe the degree of protection of data is extremely varied, with different terms used to describe the same realities and vice versa [11]. The criteria used to determine an adequate degree of protection are also problematic. Coding, double coding and anonymisation are not established in a homogeneous fashion. In addition, since anonymisation is only well suited to a restricted number of projects, due to its inherent limitations, the protection of data will vary according to the questions and norms at hand. Finally, access to research data is another major issue. The policy on access varies drastically from project to project, even within the same legislative context or ethical framework. The precise definition of "who may have access and under what conditions?" is a source of debate, both with respect to its underlying principles and with regard to the practical implementation of the conditions of access or protection. In this manner, questions of family or third-party access often lead to the decision to create different categories of data within the same biobank, which in turn complicates management of the biobank [15]. A number of questions, problems and practical modalities have been proposed for genetic epidemiology, post-genomics and biobanking [4, 7-9, 11, 34, 53-55]. Although many legal specialists remain attached to the supremacy of consent, it appears poorly adapted to protect rights in the world of networks and massive computerised processing of personal and health data over long periods of time [56]. The degree of possible identification of individuals is of course an important parameter in the level of sophistication that will be set up in order to prevent the disclosure of personal data to an unauthorised third party. In addition, the definition of the degree of protection necessary to be efficient, according to the type of data, has given rise to a large debate and caused controversies around genetic data. This is known as the issue of "Genetic exceptionalism", the belief that genetic tests generate a form of information that is unique and, therefore, justifies special consideration with regard to informed consent and privacy [4]. These various levels of controversy demonstrate the need for ongoing discussion regarding confidentiality issues and suggest that researchers and clinicians be particularly cautious and explicit on this matter.

\section{Secondary uses}

This is one of the most important features surrounding the actual use of biobanks. There is a tension between the framework and engagement of defined stakeholders surrounding a given described use of a biobank and the possibilities of further uses. They not only question the validity and extent of an individual consent but challenge all the organisations and governance of the rights to access samples and data. Who should be granted access to samples and data of "my" patients? Who should decide when there is a limited amount of material? Issues of intellectual property and rights to exclusive use may contradict the general interest and an optimised use of the biobank resource for maximising research discoveries. In 2001, the European Society of Human Genetics published its recommendation on data storage and DNA banking for biomedical research, technical, social and ethical issues, which stated the following: "The full benefits for which the subjects gave their samples will be realized through maximizing collaborative high quality research. Therefore, there is an ethical imperative to promote access and exchange information" [21]. The 2006 Council of Europe recommendation [20] on research into biological material of human origin, stresses in its preamble that "population biobanks developed on the basis of donations of biological materials made in a spirit of solidarity should not be monopolized by small groups of researchers" [20]. However, the organisation of sharing is often not precisely documented. Intellectual property issues bring about resistance, ambiguity, a lack of definition of responsibilities and, most importantly, practical difficulties for researchers [57-59]. As mentioned by the National French Bioethics Advisory Committee regarding the relationship between researchers and biobanks: "The appearance on the scene of an intermediary, the "bank", tends to spotlight issues which in fact are not new. However, certain pragmatic courses of action or compromise solutions between opposing concerns are becoming obsolete. Such is the case for relations between researchers and for the financial arrangements governing collection activities" [35].

A recent document from the UK by the Medical Research Council and The Wellcome Trust [60] addressed such issues with unprecedented clarity and detail, and may be a good basis for policy making on this topic. In addition to clarifying definitions, issues and proposing practical guidelines, rather than a simple set of principles, the UK report is very realistic: "Many academic scientists express confusion, if not consternation, over the meaning and practical implications of possession, custodianship, ownership, database rights and intellectual property (IP) generally. Some do not understand their roles inbetween the university and the funders, and some complain that they hear differing explanations from the two sides. Some are unsure as to whether materials have different IP status from data. All of this is pertinent to the sharing of data and materials. A publication from the funders explaining these matters and the alternative legal arrangements, with examples, no doubt would be enlightening" [60]. This report provides examples of the possible content of material transfer agreement and contracts of collaboration in the case of biobanks, and proposes answers to questions such as "who should decide?" The ethical dimension of such questions is obvious but most of the new codes of best practices in biobanking, such as those from the International Society of Biological and Environmental repositories, concentrate on quality and technical issues rather than on the policy of exchange [61].

\section{Public engagement and trust}

In direct relation to data access and the consent issues are the overall relationships between researchers, biobank managers 
and the public or the community. Informed consent, although indispensable, requires additional mechanisms in the general process of building trust [46-48, 52, 62, 63]. Consultation of the public is one of these mechanisms and various modalities have been explored [50, 63-65]. This dimension has been a concern for a long time for epidemiologists and population science projects, especially population genetics. However, it is a new dimension for many clinicians who are addressing the patientdoctor relationship individual dimension. Ways to introduce the collective aspects of research therefore need to be explored.

Increasingly, the public, including patient support groups, is recognised as an active participant in the elaboration and development of large-scale projects. Even in smaller projects the concept of co-construction of research involving participants or their representatives has been raised [66]. The initiation, promotion and reinforcement of dialogue between professionals and the public is gaining force, not only during the establishment of all new population databases [67] but also during the development of the legal and ethical framework and implementation [68]. However, the definition of the "public" is subject to dispute and the nature of their involvement is unclear. The need to inform, include and obtain the consent of the community or the population is put forward without specifying the character of this involvement [69-71]. Finally, the process of building trust is central to all kinds of biobank projects, whether they rely on patient or on general population studies. Well-recognised guiding principles include the need for adequate ethical and scientific supervision from the moment a biobank is created, the establishment of control mechanisms for the entire duration of research projects (ongoing monitoring) and the independence of supervising institutions. However, ethical supervision of international projects involving multiple countries raises a number of unresolved questions. The nature of this control and the bureaucratisation of the process remain acute problems. There has been little work and little documentation concerning the question of which body will supervise multi-country projects and the possibility of an eventual gradation of controls at different levels. In large projects, the concept of governance is increasingly underlined as a key factor in sustainable ethics management, but it is a thorny question. How should powers and counter-powers be established with a view to ensuring transparency and responsible conduct of research? Numerous texts (especially those specific to biobanks) discuss this issue but remain vague as to the governance and control of projects once they are approved. Governing bodies need independence and real powers in order to ensure that ethical, legal and scientific norms are respected and uniformly applied.

\section{Dissemination of results, risks and stigmatisation}

The first dimension to address is: what is a result? This may seem trivial but different points of view can be considered. Results of a study may differ on different levels. For example, when research using a biobank aims at assessing the validity of a biomarker, what is the relevant result for the researcher, patient and clinician? It may be the statistical characteristics of the test: sensitivity, specificity, positive or negative predictive values. It may also be the actual result of the test on a given individual, when not yet validated, at the beginning of the research. Or the individual result together with its interpretation from its statistical evaluation, at the end of which is often a complex aggregate. So here again, a general sentence stating that results will or will not be transmitted needs clarification and it must be made explicit what the result in question is.

The guiding principle for the dissemination of results is one of comprehensive information prior to any participation in a project, but there may be strong differences between a patientbased study and projects conducted on a scale of population, between a clinical trial form of research and a genetic study of complex diseases that can last for many years. The issue of ongoing participant information over the course of a long-term project raises certain difficulties. The right to know and the right not to know, a classical concept in genetic research, takes on new complexities in the context of population databanks due to the diversity of the data produced or processed. These data could simply be of statistical interest without any useful individual elements, or they could be of clinical interest with the possible need for genetic counselling and careful interpretation. It is worth noting that individual research results derived from population databanks are often of no clinical interest and can lead to misinterpretations due to the fact that they are based on incomplete information (often, biobanks are not accompanied by access to the participant's complete medical record). In addition, the rare cases in which validated individual results are provided to participants, there may be the need for genetic counselling measures, which are not anticipated in the research context. Therefore, in many cases, individual reporting is not planned for, since the results are usually aggregated and considered to be of purely scientific interest, but the right to be aware of information about ones self is a counter-balancing principle. The individualistic trend of classical ethics is questioned in the biobank context [45]. The individual usefulness (or not) of results, the consideration of potential risks and the stigmatisation merit careful consideration. Due to the sensitive nature of certain genetic data, such data can entail risks of discrimination or stigmatisation within populations or communities. These risks must be recognised, both with respect to recruitment and interpretation of results, by properly informing participants and by taking action to avoid or minimise their occurrence. However, informing participants of the risks of stigmatisation combined with "misinformation" on the nature of biobanks can have a negative impact on recruitment and can even introduce biases. Providing participants with too many details on the remote possibility of stigmatisation may alarm them and lead them to question the legitimacy and true nature of the proposed research (to say nothing of reinforcing genetic exceptionalism). As discriminatory events cannot be easily foreseen, it is therefore impossible to inform properly about their actual occurrence and features. In this case, transparency leads to imprecision and may even breed scepticism.

\section{Commercialisation and benefit sharing}

Although the general principle that "biological materials should not, as such, give rise to financial gains" (as recalled in the Council of Europe recommendation of 2006 [20]) the acknowledgement of the commercial aspects of biobanks is recognised [51, 72, 73]. Rather than defining the exact meaning of "as such", efforts are focused on the need to elaborate on the policy of the sharing or distribution of eventual profits or 
benefits. In practice, great uncertainties arise here with respect to establishing guiding principles and ensuring clarity; this is due to the variable and changing nature of project financing (public versus private or semi-private projects) and to the continuing ambiguous status of genetic material for which numerous elements must be taken into account (property rights, remuneration or compensation of participants, financial gains, royalties, other types of gain, beneficiaries). Debate over property rights of biological material is currently very active [74]. The present article underlines the fact that most current research regulations are built on a theory of autonomy, which is independent of any property right in one's tissue. Thus, although, in general, patients can refuse or consent to the donation of tissue samples for research, such rights are legally quite limited. "If the (property right) pattern extended to tissues, then selling organs might become a matter of right. And cadaveric tissue could become the property of heirs, rendering unusable even old repositories such as the one used to sequence the 1918 influenza virus" [74]. Therefore, the status of biological samples is initially an unresolved question; they can be considered to be either completely out of the commercial sphere as body parts, or not if they are covered by property rights. Another ambiguity is the unclear limit between the renumeration of donors, which is often not permitted, and compensation of their expenses and time related to their participation in the project, which is usually permitted. Finally, the issue of direct involvement of private companies in biobank projects may also create anbiguities regarding financial benefits derived from the use of free donation. Even if relatively rare in population studies, such participation remains controversial since biobanks intermingle notions of property shared by all of humanity with population and individual considerations. The participation of companies is more developed in terms of conditions of access to patients' samples and data. In case of benefits being generated, it is very unclear with whom and by which mechanisms they should be shared; various models have been proposed but even guiding principles remain unclear. This concept of benefit sharing must be balanced with the notion of "public good" and population health that constitute biobanks $[63,75]$.

Thus, many legal and ethical controversies arise on the subject of biobanks. A general trend stresses that a great deal of thought should accompany the preparation of any protocol in its ethical dimensions. Methodological design in genetic epidemiology and post-genomic research are in fact intimately linked with ethical issues. Most of the difficult issues may become easier to deal with, by making explicit in each case the various aspects mentioned previously and by allowing the participants to express themselves at the start of the study, whether this is required by law or not.

\section{PRESENT TRENDS AND DISCUSSION}

Three main controversial and evolving topics dominate the debate: 1) informed consent; 2) confidentiality; and 3) the sharing of data and results. There is a trend to the proliferation of texts at all levels. Both principles and modalities of applications are challenged and new developments are triggered by the growing interest in large-scale projects, both patient-based and population-based, with a strong international component. The challenge of harmonisation and networking is huge and a number of recent initiatives address it. Among them, the P3G consortium (Public Population Projects in Genomics) [76] must be mentioned. PG3 is a notfor-profit international consortium to promote collaboration between researchers in the field of population genomics. It has been launched in order to provide the international population genomics community with the resources, tools and know-how to facilitate data management for improved methods of knowledge transfer and sharing. Its main objective is the creation of an open, public and accessible knowledge database. The PG3 motto is precision and collaboration, and ethical and societal issues are fully considered. In addition, at European level, a very recent initiative has been launched [77]; a panEuropean and broadly accessible network of existing and de novo biobanks and biomolecular resources. The infrastructure will include samples from patients and healthy persons, molecular genomic resources and bioinformatics tools to optimally exploit this resource for global biomedical research. A coordination action entitled Promoting Harmonization Of Epidemiological Biobanks in Europe (PHOEBE) also concentrates on population biobanks and cohorts [78]. It was started in 2006 in collaboration with P3G and also fosters networking. It underlines the integration of ethical and societal issues as one of the axes of work. Thus, it seems that after a long period of relative "protectionism" of rather small collections by their promoters, where sharing of resources was left under control of the biobank under rather loose organisation and governance models [54], an era of larger sharing and harmonisation is emerging at the same time as large-size projects. This movement is accompanied by an active integration of the ethical challenges as part of such projects. Whereas the need for some level of international consensus on principles is recognised and some trends demonstrate coherence, when comparing national contexts, inconsistencies are striking and include: 1) development of biobank specific legislation; 2) self-regulation; and 3) adaptation of existing legislation in order to incorporate the characteristics of biobanks. The main tendencies towards convergence and the points of disagreement are summarised in table 2. In practice, for biobanking in genetic epidemiology, post-genomic research and population genetics, the main trends of practical importance found in recent documents may be summarised as follows. 1) Allow for the possibility of deviating from the traditional principle of explicit re-consent for future use of samples collected for a specific research purpose, as long as the privacy/confidentiality of the research sample is ensured. 2) Automatic irreversible anonymisation of samples as the expedient solution to the ethical and legal quandaries is being questioned and re-examined and double coding is emerging as the preferred option in many situations for both scientific and ethical reasons. 3) Prevention of general/blanket consent for future unspecified uses of both research samples and left-over samples from medical care without a specific consent is increasingly nuanced; and developing recognition of the ethical validity of broad or general consent to genetic research or banking, especially for longitudinal studies, provided there is ongoing monitoring and ethical approval is recommended. 4) Increasing the role of research ethics committees for biobank management and follow-up is a recommended policy. 5) Developing mechanisms for independent monitoring and governance of biobanks 
with the involvement of participants at different levels of projects is pushed forward.

Table 2 also highlights the fact that difficulties exist in the common understanding of the various issues and the accompanying procedures; many differences and interpretations exist. However, developments can be foreseen with some optimism in the maze of regulatory texts and contrasted positions. Many different clinical and scientific fields are interested in biobank-related aspects as progress of knowledge in these fields is dependent on such resources. Each discipline has already envisaged the issues and often worked out acceptable solutions to some of them; the international projects cited above allow exchanges between these fields. For example, issues resolved in population genetics may in turn be adapted to large-scale genetic epidemiology projects [79]. Pathology societies and cancer institutes have addressed a lot of the questions surrounding the use of archived collections and their solutions may apply to other fields [80, 81]. The advantage of such professional groups is that they have often worked across country frontiers [21, 23]. The more recent collaboration between scientists, jurists, philosophers, social scientists and policy makers as part of biobank projects that actually are research infrastructures rather than individual projects, and the involvement of the participant representatives in their governance bodies, provides hope that common understanding will occur.

In conclusion, ethical debate is triggered by the current developments but can also precede it. The construction and use of large biobanks as research infrastructures for common diseases, genetic epidemiology and post-genomic studies seems irreversible. In this challenging domain the overall precision at all steps of the projects, prudence and openness, appear to be important elements that will make it possible to envisage the eventual application of the new knowledge generated through biobanks in the domain of public health.

\section{REFERENCES}

1 Holland NT, Pfleger L, Berger E, Ho A, Bastaki M. Molecular epidemiology biomarkers--sample collection and processing considerations. Toxicol Appl Pharmacol 2005; 206: 261-268.

2 Steinberg K, Beck J, Nickerson D, et al. DNA banking for epidemiologic studies: a review of current practices. Epidemiology 2002; 13: 246-254.

3 Kauffmann F. Post-genome respiratory epidemiology: a multidisciplinary challenge. Eur Respir J 2004; 24: 471-480.

4 Cambon-Thomsen A. The social and ethical issues of postgenomic human biobanks. Nat Rev Genet 2004; 5: 866-873.

5 Tutton R, Corrigan O. Genetic Databases: Socio-Ethical Issues in the Collection and Use of DNA. London, Routledge, 2004.

6 Australian Law Reform Commission. Essentially Yours: The Protection of Human Genetic Information in Australia. www.alrc.gov.au/media/2003/mr2905.htm. Date last updated: July 2005. Date last accessed: May 25, 2007.

7 Knoppers BM. Biobanking: international norms. J Law Med Ethics 2005; 33: 7-14.
8 Joly Y, Knoppers BM, Nguyen MT. Stored tissue samples: through the confidentiality maze. Pharmacogenomics J 2005; 5: 2-5.

9 Martin Uranga A, Martin Arribas MC, Jaeger C, Posadas M. Outstanding ethical-legal issues on biobanks. An overview on the regulations of the Member States of the Eurobiobank project. Law Hum Genome Rev 2005; 22: 103-114.

10 Kaye J. Do we need a uniform regulatory system for biobanks across Europe? Eur J Hum Genet 2006; 14: 245-248.

11 Knoppers BM, Saginur M. The Babel of genetic data terminology. Nat Biotechnol 2005; 23: 925-927.

12 Elston RC, Olson JM, Palmer L. Biostatistical Genetics and Genetic Epidemiology. 1st Edn. Chichester, John Wiley \& Sons, 2002.

13 Barnetche T, Gourraud PA, Cambon-Thomsen A. Strategies in analysis of the genetic component of multifactorial diseases; biostatistical aspects. Transpl Immunol 2005; 14: 255-266.

14 Matthiessen L, Pitkänen K, eds, European Commission Research Directorate-General. Survey on opinions from National Ethics Committees or similar bodies, public debate and national legislation in relation to human biobanks. Directorate E: Biotechnology, Agriculture and Food, 2004. http://ec.europa.eu/research/biosociety/ pdf/catalogue_biobanks.pdf Date last updated: May 25, 2007.

15 Cambon-Thomsen A, Sallée C, Rial-Sebbag E, Knoppers BM. Populational genetic databases: is a specific ethical and legal framework necessary? GenEdit 2005; 3: 1-13.

16 HumGen. University of Montreal, 2006. www.humgen. umontreal.ca/int/ Date last accessed: May 25, 2007.

17 The World Medical Association (WMA). World Medical Association Declaration of Helsinki Ethical Principles for Medical Research Involving Human Subjects, 2000. www.wma.net/e/policy/b3.htm Date last accessed: May 25, 2007.

18 Council for International Organizations of Medical Sciences (CIOMS). International Ethical Guidelines for Biomedical Research Involving Human Subjects. Geneva, World Health Organization, 2002.

19 Council of Europe. Additional Protocol to the Convention on Human Rights and Biomedicine Concerning Biomedical Research. Strasbourg, 2005. www.coe.int/T/E/ Legal_Affairs/Legal_co-operation/Bioethics / Activities / Biomedical_research/195\%20Protocole $\% 20$ recherche $\% 20$ biomedicale\%20e.pdf Date last accessed: May 25, 2007.

20 Council of Europe. Recommendation (Rec 2006/4) of the Committee of Ministers to Member States on Research on Biological Material of Human Origin. Strasbourg, 2006. www.coe.int/t/e/legal_affairs/legal_co-operation/bioethics/ texts_and_documents/Rec_2006_4.pdf Date last accessed: May 25, 2007.

21 European Society of Human Genetics. Data Storage and DNA Banking for Biomedical Research: Technical, Ethical and Social Issues, 2001. www.eshg.org/ESHGDNAbankingrec. pdf. Date last accessed: May 25, 2007.

22 The World Medical Association. The World Medical Association Declaration on Ethical Considerations Regarding Health Databases. Washington, 2002. www.wma. net/e/policy/d1.htm Date last accessed: May 25, 2007. 
23 The Human Genome Organization (HUGO). HUGO Ethics Committee: Statement on Human Genomic Databases, 2002. www.hugo-international.org/Statement_on_Human_ Genomic_Databases.htm Date last accessed: May 25, 2007.

24 World Health Organization-Organisation Mondiale de la Santé. Genetic Databases: Assessing the Benefits and the Impact on Human and Patient Rights, 2003. www.law. ed.ac.uk/ahrb/publications/online/whofinalreport.pdf Date last accessed: May 25, 2007.

25 United Nations Educational, Scientific and Cultural Organization. International Declaration on Human Genetic Data. Paris, 2003. http://portal.unesco.org/en/ev.phpURL_ID $=17720 \& U R L \_D O=D O \_T O P I C \& U R L \_S E C T I O N$ =201.html Date last accessed: May 25, 2007.

26 McNally E, Cambon-Thomsen A, Brazell A, et al. 25 Recommendations on the Ethical, Legal and Social Implications of Genetic Testing. http://europa.eu. int/comm/research/conferences / 2004/genetic/pdf / recommendations_en.pdf Date last accessed: May 25, 2007.

27 Directive 2004/23/EC of the European Parliament and of the Council of 31 March 2004 on setting standards of quality and safety for the donation, procurement, testing, processing, preservation, storage and distribution of human tissues and cells. http://europa.eu.int/smartapi/ cgi/sga_doc?smartapi!celexapi!prod!CELEXnumdoc\&lg= en\&numdoc $=32004 \mathrm{~L} 0023 \&$ model $=$ guicheti Date last accessed: May 25, 2007.

28 Commission Directive 2006/17/EC of 8 February 2006 implementing Directive 2004/23/EC of the European Parliament and of the Council as regards certain technical requirements for the donation, procurement and testing of human tissues and cells. http://europa.eu.int/smartapi/ cgi/sga_doc?smartapi!celexapi!prod!CELEXnumdoc\&lg= en\&model $=$ guicheti\&numdoc $=32006$ L0017 Date last accessed: May 25, 2007.

29 McNally E, Cambon-Thomsen A, Brazell A, et al. The Independent Expert Group. Ethical, Legal and Social Aspects of Genetic Testing: Research, Development and Clinical Applications. http://europa.eu.int/comm/ research/conferences/2004/genetic/report_en.htm Date last accessed: May 25, 2007.

30 Rial-Sebbag E. [Conditions for using human biological samples in scientific research: legal and ethical framework]. Med Sci (Paris) 2006; 22: 8-14.

31 Rial-Sebbag E. [Legal aspects of biological sample banks]. Rev Epidemiol Sante Publique 2003; 51: 111-119.

32 Cambon-Thomsen A, Rial-Sebbag E. [Ethical aspects of biological sample banks]. Rev Epidemiol Sante Publique 2003; 51: 101-110.

33 Cambon-Thomsen A, Rial-Sebbag E, Duchier J. [Ethical and legal aspects of biological sample banks: synthesis, practical questions and proposals]. Rev Epidemiol Sante Publique 2003; 51: 121-126.

34 Gillott J, Genetic Interest Group, Human Rights, Privacy and Medical Research: Analysing UK Policy on Tissue and Data, 2006. www.gig.org.uk/docs/hrprivacypdf190506. pdf Date last accessed: May 25, 2007.

35 National Consultative Ethics Committee for Health and Life Sciences (CCNE). Ethical Problems Raised by the Collected Biological Material and Associated Information
Data: "Biobanks", "Biotheques". Report No. 77. Paris, France, 2003.

36 Capron AM, Biller-Andorno N, Mauron A, Elger B, Boggio A. Human genetic databases: towards a global ethical framework. World Health Organisation, 2006. www.who. int/ethics/topics/hgdb/en/print.html Date last accessed May 25, 2007.

37 Knoppers BM. Biobanks: simplifying consent. Nat Rev Genet 2004; 5: 485.

38 Knoppers BM. Consent revisited: points to consider. Health Law Rev 2005; 13: 33-38.

39 Holm S. Informed consent and the bio-banking of material from children. Genomics, Society and Policy 2005; 1: 16-26.

40 Knoppers BM, Avard D, Cardinal G, Glass KC. Science and society: children and incompetent adults in genetic research: consent and safeguards. Nat Rev Genet 2002; 3 221-225.

41 Deschenes M, Cardinal G, Knoppers BM, Glass KC. Human genetic research, DNA banking and consent: a question of "form"? Clin Genet 2001; 59: 221-239.

42 Hansson MG, Dillner J, Bartram CR, Carlson JA, Helgesson G. Should donors be allowed to give broad consent to future biobank research? Lancet Oncol 2006; 7: 266-269.

43 Helgesson G, Johnsson L. The right to withdraw consent to research on biobank samples. Med Health Care Philos 2005; 8: 315-321.

44 Maschke KJ. Alternative consent approaches for biobank research. Lancet Oncol 2006; 7: 193-194.

45 Williams G. Bioethics and large-scale biobanking: individualistic ethics and collective projects. Genomics, Society and Policy 2005; 1: 50-66.

46 Ducournau P. Le consentement à la recherche en épidémiologie génétique: un rituel de confiance en question. [Informed consent in genetic epidemiology research: a ritual of trust questioned.]. Sci Soc Sante 2005; 23: 5-36.

47 Ducournau P. DNA donors' viewpoint on the consent device. New Genet Soc 2007 (in press).

48 Hoeyer K, Olofsson BO, Mjorndal T, Lynoe N. Informed consent and biobanks: a population-based study of attitudes towards tissue donation for genetic research. Scand J Public Health 2004; 32: 224-229.

49 Kettis-Lindblad A, Ring L, Viberth E, Hansson MG. Genetic research and donation of tissue samples to biobanks. What do potential sample donors in the Swedish general public think? Eur J Public Health 2006; 16: 433-440.

50 Nilstun T, Hermeren G. Human tissue samples and ethics: attitudes of the general public in Sweden to biobank research. Med Health Care Philos 2006; 9: 81-86.

51 Rothstein MA. The role of IRBs in research involving commercial biobanks. J Law Med Ethics 2002; 30: 105-108.

52 de Montgolfier S, Moutel G, Duchange N, et al. Evaluation of biobank constitution and use: multicentre analysis in France and propositions for formalising the activities of research ethics committees. Eur J Med Genet 2006; 49: 159-167.

53 Eriksson S, Helgesson G. Potential harms, anonymization, and the right to withdraw consent to biobank research. Eur J Hum Genet 2005; 13: 1071-1076. 
54 Hirtzlin I, Dubreuil C, Preaubert N, et al. An empirical survey on biobanking of human genetic material and data in six EU countries. Eur J Hum Genet 2003; 11: 475-488.

55 Knoppers BM. Duty to recontact: a legal harbinger? Am J Med Genet 2001; 103: 277.

56 Chassigneux C, Trudel P, Knoppers BM. The legal framing of computerized processing of health data: a European and Canadian prespective. GenEdit 2006; 4: 1-8.

57 Cambon-Thomsen A. Assessing the impact of biobanks. Nat Genet 2003; 34: 25-26.

58 Caulfield TA, Knoppers BM, Gold ER, Sheremeta LE, Bridge PJ. Genetic technologies, health care policy and the patent bargain. Clin Genet 2003; 63: 15-18.

59 Chokshi DA, Parker M, Kwiatkowski, DP., Data sharing and intellectual property in a genomic epidemiology network: policies for large-scale research collaboration. Bull World Health Organ 2006; 84: 382-387.

60 Medical Research Council (MRC), The Wellcome Trust. Access to Collections of Data and Materials for Health Research. London, 2006.

61 International Society for Biological and Environmental Repositories. Best practices for repositories I: Collection, storage, and retreival of human biological materials for research. Cell Preserv Technol 2005; 3: 5-48.

62 Hoeyer K, Olofsson BO, Mjorndal T, Lynoe N. The ethics of research using biobanks: reason to question the importance attributed to informed consent. Arch Intern Med 2005; 165 : 97-100.

63 Knoppers BM. Population genetics and benefit sharing. Community Genet 2000; 3: 212-214.

64 Godard B, Marshall J, Laberge C, Knoppers BM. Strategies for consulting with the community: the cases of four largescale genetic databases. Sci Eng Ethics 2004; 10: 457-477.

65 Laberge C, Knoppers BM, Panisset I. Multidisciplinary perceptions of human genetics in Canada: "Delphi" results with regards to the practice of medical genetics. Health Law J 1995; 3: 19-57.

66 Ducournau P. Consentement éclairé et recherche en génétique humaine: essai de socio-éthique. Thèse Sociologie. [Informed consent in human genetics research : an assay in socio-ethics.] PhD thesis, Paul Sabatier University, Toulouse, France, 2005.
67 Knoppers BM, Chadwick R. Human genetic research: emerging trends in ethics. Nat Rev Genet 2005; 6: 75-79.

68 Sharp RR, Foster MW. Involving study populations in the review of genetic research. J Law Med Ethics 2000;28, 41-51:3.

69 Foster MW, Eisenbraun AJ, Carter TH. Communal discourse as a supplement to informed consent for genetic research. Nat Genet 1997; 17: 277-279.

70 Greely HT. Informed consent and other ethical issues in human population genetics. Annu Rev Genet 2001; 35: 785-800.

71 Knoppers BM. Populations and Genetics. Legal and SocioEthical Perspectives. Leiden, Martinus Nijhoff, 2003.

72 Kaiser J. Biobanks. Private biobanks spark ethical concerns. Science 2002; 298: 1160.

73 Bellivier F, Noiville C, Ghestin J, eds. Contrats et vivant. Les droits de la circulation des ressources biologiques. [Contracts and Living Elements: Rights on Circulation of Biological Resources.] LGDJ, France, 2006.

74 Charo RA. Body of research--ownership and use of human tissue. N Engl J Med 2006; 355: 1517-1519.

75 Knoppers BM. Of genomics and public health: building public "goods"? CMAJ 2005; 173: 1185-1186.

76 Public Population Projects in Genomics, P3G. www.p3gconsortium.org Date last accessed: May 25, 2007.

77 European Biobanks: United Facility. www.biobanks.eu/ Date last accessed: May 25, 2007.

78 Population Biobanks. PHOEBE: Promoting Harmonisation of Epidemiological Biobanks in Europe. www.population biobanks.org/eway/default.aspx Date last accessed: May 25, 2007.

79 Quebec Network of Applied Genetic Medicine (RMGA). Statement of Principles on the Ethical Conduct of Genetic Research Involving Populations, 2002. www.rmga.qc.ca/ en/index.htm Date last accessed: May 25, 2007.

80 National Cancer Institute. First-Generation Guidelines for NCI-Supported Biorepositories, 2006. http://biospecimens. cancer.gov/biorepositories/guidelines.asp Date last accessed: May 25, 2007.

81 Borella L, Lubin R, Dupont M, Janin A. Guidelines for the collection, conservation and use of human biological samples in the field of cancer. Bulletin du cancer 2006; 93: 197-212. 